\title{
PERBANDINGAN IMPLEMENTASI SCIENTIFIC LEARNING PADA MATA PELAJARAN PENDIDIKAN AGAMA ISLAM (PAI) DALAM PENGUATAN KESADARAN BERAGAMA PADA SISWA TUNAGRAHITA DI SLB PEMBINA YOGYAKARTA DENGAN SLB MUHAMMADIYAH GAMPING
}

\author{
Arif Mahfud \\ Program Pasca Sarjana \\ Universitas Muhammadiyah Yogyakarta \\ E-mail: fud.kader@gmail.com
}

\begin{abstract}
Abstrak
Penelitian ini bertujuan untuk mengetahui: (1) Proses pembelajaran PAI siswa tunagrahita jenjang SDLB di SLB Negeri Pembina Yogyakarta dalam menerapkan scientific learning, (2) Proses pembelajaran PAI siswa tunagrahita jenjang SDLB di SLB Muhammadiyah Gamping dalam menerapkan scientific learning, (3) Keberhasilan peningkatan keagamaan siswa tunagrahita jenjang SDLB di SLB Negeri Pembina Yogyakarta, (4) Keberhasilan peningkatan keagamaan siswa tunagrahita jenjang SDLB di SLB Muhammadiyah Gamping, dan (5) Strategi sekolah mengatasi hambatan pembelajaran siswa untuk menguatkan keagamaan siswa tunagrahita jenjang SDLB. Jenis penelitian yang digunakan yaitu deskriptif kualitatif dengan pendekatan fenomenologi. Lokasi penelitian yaitu SLB Negeri Pembina Yogyakarta dan SLB Muhammadiyah Gamping. Teknik pengumpulan data menggunakan observasi, wawancara, dan dokumentasi. Hasil Penelitian ini: (1) Materi pembelajaran PAI dalam menerapkan scientific learning, (2) Materi pembelajaran PAI di SLB Muhammadiyah Gamping meliputi akidah dan akhlak., (3) Kegiatan keagamaan siswa tunagrahita jenjang SDLB di SLB Negeri Pembina Yogyakarta berhasil meningkat, (4) Kegiatan keagamaan siswa tunagrahita jenjang SDLB di SLB berhasil meningkat. (5) Strategi dalam mengatasi kendala disesuaikan dengan kendala dan faktor pendukung yang dimiliki.
\end{abstract}

Kata kunci : scientific learning, SLB, tunagrahita, pendidikan agama islam

\begin{abstract}
This study aims to find out: (1) The learning process of PAI for mentally retarded SDLB students in SLB Yogyakarta Fostering State in implementing scientific learning, (2) The learning process of PAI learning for mentally retarded SDLB students at SLB Muhammadiyah Gamping in implementing scientific learning, (3) religious retarded SDLB level students in SLB Yogyakarta State Guidance, (4) Successful improvement of SDLB mentally retarded religious students at SLB Muhammadiyah Gamping SLBs, and (5) School strategies to overcome barriers to student learning to strengthen the religious retardation of SDLB students. The type of research used is descriptive qualitative with a phenomenological approach. The research locations are SLB Yogyakarta and SLamping Muhammadiyah Gamping SLB. Data collection techniques using observation, interviews, and documentation. The results of this study: (1) PAI learning material in applying scientific learning, (2) PAI learning material in SLB Muhammadiyah Gamping includes creeds and morals, (3) Religious activities for mentally retarded SDLB students in SLB Negeri Pembina Yogyakarta have increased, (4 ) Religious activities for mentally retarded SDLB students at SLB have increased. (5) Strategies in overcoming obstacles are adjusted to the constraints and supporting factors they have.
\end{abstract}

Keywords: scientific learning, SLB, mental retardation, Islamic religious education

\section{Info Artikel}

Diterima Februari 2020, disetujui Maret 2020, diterbitkan Juni 2020

Dipublikasikan Oleh: Program Studi Bimbingan dan Konseling 


\section{PENDAHULUAN}

Pendidikan merupakan hak setiap anak yang tertuang dalam Undang-Undang Dasar 1945 Pasal 31 ayat (1), "Setiap warga negara berhak mendapatkan pendidikan". Setiap anak yang dimaksudkan termasuk kelainan fisik, mental, sosial, intelektual dan atau sosial dengan mengikuti pendidikan khusus seperti yang diatur dalam UU No.20 Tahun 2003, dalam Pasal 5 ayat (2). Salah satu anak berkebutuhan khusus adalah tunagrahita.

Istilah tunagrahita digunakan untuk menyebut anak yang memiliki kemampuan intelektual di bawah rata-rata. Dalam kosakata asing disebut dengan istilah-istilah mental retardation, mentally retarded, mental decendency, mental defective, dan sebagainya (Soemantri, 2006: 106).

Menurut Brown et al. yang dikutip dalam Direktorat Pendidikan Luar Biasa menyebutkan 7 karakteristik tunagrahita yaitu:

1. Lamban mempelajari hal baru, sulit mempelajari pengetahuan abstrak, serta mudah lupa dengan yang dipelajari tanpa latihan yang terus menerus.

2. Mengalami kesulitan dalam mempelajari hal-hal yang baru.

3. Tunagrahita berat memiliki kekurangan dalam kemampuan bicara.

4. Kekurangan fisik serta perkembangan gerak.

5. Kemampuan mandiri sangat rendah.

6. Tingkah laku dan interaksi yang tidak lazim.

7. Tingkah laku kurang wajar yang terus menerus.

Karakter tersebut membuat anak-anak tungrahita cukup mengalami kesulitan dalam mengikuti pembelajaran di sekolah yang saat ini menggunakan pendekatan kurikulum 2013 atau dikenal dengan scientific learning. Pembelajaran dengan pendekatan scientific adalah proses pembelajaran yang dirancang sedemikian rupa agar peserta didik secara aktif mengkonstruksikan konsep, hukum atau prinsip melalui tahapan-tahapan mengamati (untuk mengidentifikasi atau menemukan masalah), merumuskan masalah, mengajukan atau merumuskan hipotesis, mengumpulkan data dengan berbagai teknik, menganalisis data, menarik kesimpulan, dan mengkomunikasikan konsep, hukum atau prinsi yang "ditemukan". Pembelajaran pendekatan scientific dalam pembelajaran melibatkan keterampilan proses seperti 
mengamati, mengklasifikasikan, mengukur, meramalkan, menjelaskan, dan menyimpulkan (Daryanto, 2014: 51).

Penerapan scientific learning dalam mata pelajaran Pendidikan Agama Islam di SLB tingkat pendidikan dasar diharapkan dapat membangun kesadaran beragama bagi setiap siswa tunagrahita. Meskipun kurikulum ini masih tergolong awal, namun setiap SLB sudah mulai menerapkan baik sekolah yang belum lama berdiri maupun yang sudah lama berdiri. Salah satu SLB yang sudah lama berdiri adalah SLB Negeri Pembina Yogyakarta yang berada di Giwangan, Yogyakarta. Sekolah ini mulai beroperasi pada tahun 2006 dan menjadi pusat pendidikan khusus yang disebut dengan Sentra PKPLK (Sentra Pendidikan Khusus dan Pendidikan Layanan Khusus) yang memiliki program utama mengembangkan keterampilan anak berkebutuhan khusus untuk mempersiapkannya agar mampu terjun ke masyarakat seperti anak normal lainnya. Sekolah Luar Biasa lainnya yang belum lama beroperasi yaitu SLB Muhammadiyah Gamping, Sleman yaitu tahun 2012.

\section{METODE PENELITIAN}

Penelitian ini merupakan penelitian deskriptif kualitatif dengan pendekatan fenomenologi. Lokasi penelitian yaitu SLB Negeri Pembina Yogyakarta dan SLB Muhammadiyah Gamping. Teknik pengumpulan data menggunakan observasi, wawancara, dan dokumentasi. Analisis data menggunakan analisis deskriptif kualitatif yang meliputi reduksi data, penyajian data dan penarikan kesimpulan.

\section{HASIL DAN PEMBAHASAN}

\section{Pembelajaran PAI di SLB Negeri Pembina Yogyakarta}

Kurikulum 2013 di SLB Negeri Pembina Yogyakarta mulai diterapkan tahun pada tahun 2016. Pembelajaran PAI di SLB Negeri Pembina Yogyakarta jenjang Sekolah dasar ini diampu oleh 2 guru Pendidikan Agama Islam yang masing-masing guru mengampu 50 siswa. Adapun pembelajaran Pendidikan Agama Islam ini meliputi materi, metode, dan media pembelajaran untuk siswa tunagrahita. 


\section{Materi Scientific Learning (Kurikulum 2013)}

Materi scientific learning untuk anak tunagrahita memiliki tingkat lebih ringan dibandingkan untuk anak normal. Hal ini mengingat anak tunagrahita memiliki kemampuan di bawah anak normal dalam memahami sesuatu. Siswa tunagrahita di SLB Negeri Pembina Yogyakarta dikategorikan ringan, yaitu dengan IQ antara 51-70.

\section{Metode}

Metode yang digunakan untuk menyampaikan materi pelajaran yaitu metode yang mudah dipahami oleh anak. Di SLB Negeri Pembina Yogyakarta, metode yang digunakan yaitu metode ceramah, bercerita dan kisah-kisah, tanya jawab, latihan, dan demonstrasi.

\section{Media}

Media yang digunakan untuk menyampaikan materi pelajaran Pendidikan Agama Islam di SLB Negeri Pembina Yogyakarta sudah banyak mengingat kemampuan daya tangkap siswa tunagrahita sehingga dapat menunjang siswa untuk lebih memahami materi yang disampaikan oleh guru. Media yang digunakan untuk menyampaikan materi kepada siswa meliputi media visual, media audio, serta audio visual.

\section{Pembelajaran PAI di SLB Muhammadiyah Gamping}

Sekolah Luar Biasa (SLB) Muhammadiyah Gamping memiliki guru Pendidikan Agama Islam untuk jenjang Sekolah Dasar sebanyak 1 orang yang mengampu siswa tunagrahita jenjang Sekolah Dasar sebanyak 19 siswa. Selain tunagrahita, guru tersebut juga mengampu anak berkebutuhan khusus lainnya yaitu tunadaksa, autis, dan tunawicara ringan.

\section{Materi Scientific Learning (Kurikulum 2013)}

Siswa tunagrahita di SLB Muhammadiyah Gamping merupakan tingkat ringan. Materi Pendidikan Agama Islam yang disampaikan kepada siswa meliputi akidah dan akhlak. 


\section{Metode}

Metode yang digunakan dalam menyampaikan materi Pendidikan Agama Islam untuk siswa tunagrahita menggunakan metode ceramah, bercerita, tanya jawab, latihan, dan demonstrasi.

\section{Media}

Media pembelajaran di SLB Muhammadiyah Gamping yaitu white board, laptop, rekaman, dan gambar. Adapun media yang paling sering digunakan untuk siswa tunagrahita yaitu white board, rekaman, dan gambar (misalnya gambar tata cara sholat, tata cara wudhu, tulisan doa sehari-hari, dan sebagainya).

\section{Peningkatan Keagamaan Siswa SLB Negeri Pembina Yogyakarta}

Dalam pendekatan scientific learning, evaluasi dilakukan terhadap pencapaian siswa tunagrahita dalam mata pelajaran Pendidikan Agama Islam. Pencapaian siswa tunagrahita tersebut maka penilaian dilakukan terhadap 3 aspek yaitu sikap spiritual, sikap sosial, pengetahuan, dan keterampilan. Untuk mengukurnya digunakan tes dan pengamatan kepada tiap siswa. Guru akan menilai kemampuan siswa dalam praktik saat mengikuti pembelajaran, serta tes tulis dan lisan juga digunakan untuk mengukur kemampuan akademik.

\section{Peningkatan Keagamaan Siswa SLB Muhammadiyah Gamping}

Keberhasilan peningkatan keberagama siswa tunagrahita jenjang SDLB di SLB Negeri Pembina Yogyakarta diukur dengan cara mengan mengadakan tes sesuai dengan instrumen yang digunakan, tes lisan sebagai tugas proyek, dan tes tertulis sebagai tugas praktek.

\section{Perbedaan Pembelajaran Scientific Learning di Kedua SLB \\ Sekolah Luar Biasa (SLB) Negeri Pembina Yogyakarta}

Kendala yang menghambat pembelajaran di SLB Negeri Pembina Yogyakarta meliputi buku materi yang berasal dari pemerintah perlu dikaji ulang dan disesuaikan dengan kemampuan dan kebutuhan anak tunagrahita, sehingga jika tidak ada buku materi baik untuk siswa maupun guru maka pihak sekolah tidak memiliki acuan dalam 
penyampaian materi. Selain itu, keterbatasan jumlah guru yang mengampu juga menjadi kendala tersendiri. Guru pengampu di SLB Negeri Pembina Yogyakarta hanya berjumlah 1 orang yang harus memberikan materi kepada 100 siswa dan terbagi dalam 2 kelas.

Untuk mengatasi kendala-kendala yang dihadapi maka sekolah ini memanfaatkan faktor pendukung yang ada yaitu:

1. Sumber daya manusia yaitu guru PAI yang telah mengikuti diklat K13 dan membuat buku K13

2. Mengoptimalkan penggunaan sarana dan prasarana sekolah seperti mushola, perpustakaan, dan media pembelajaran

3. Memanfaatkan anggaran yang diberikan pemerintah untuk memaksimalkan implementasi kurikulum misalnya mencetak buku, mengembangkan sarana belajar agar tercipta suasana menyenangkan dalam belajar, dan sebagainya.

\section{Sekolah Luar Biasa (SLB) Muhammadiyah Gamping}

Kendala yang dihadapi dalam implementasi kurikulum 2013 di SLB Muhammadiyah Gamping, yaitu:

1. Kurangnya fasilitas yang memadai

2. Belum adanya buku guru yan dibuat oleh pihak terkait

3. Sistem pendidikan masa lalu yang masih diterapkan sampai saat ini

SLB Muhammadiyah Gamping pun berusaha untuk mengatasi berbagai kendala yang dihadapi, yaitu dengan:

1. Mendorong guru untuk lebih kreatif, misalnya menyusun sendiri bahan ajar untuk digunakan di internal sekolah sebagai penunjang.

2. Mencari sumber belajar lain, misalnya studi banding dengan sekolah lain yang lebih lama menangani siswa berkebutuhan khusus.

3. Menyesuaikan dengan keadaan, misalnya tidak terlalu memberikan beban kepada siswa mengenai kemampuan akademisnya dan tetap mendorong setiap siswa mampu terlibat dalam pembelajaran tanpa merasa tertekan.

4. Memanfaatkan dan mengoptimalkan potensi dan faktor pendukung yang sudah ada yaitu guru-guru yang sudah mengikuti diklat kurikulum 2013 dan media pembelajaran yang sudah ada. 
Secara umum, perbedaan pembelajaran PAI dalam menerapkan scientific learning dalam menguatkan keagamaan siswa tunagrahita jenjang SDLB di SLB Negeri Pembina Yogyakarta dan SLB Muhammadiyah Gamping dapat disajikan pada tabel berikut :

Tabel 1. Pembelajaran PAI dengan scientific learning

\begin{tabular}{|c|c|c|c|}
\hline No. & $\begin{array}{c}\text { Pembelajaran } \\
\text { Scientific Learning }\end{array}$ & SLB Pembina Yogyakarta & SLB Muhammadiyah Gamping \\
\hline 1. & Materi & $\begin{array}{l}\text { 1. Akidah (melalui rukun } \\
\text { iman) } \\
\text { 2. Praktik sholat berjamaah } \\
\text { 3. Hafalan surat pendek } \\
\text { dalam Al-Qur'an dan } \\
\text { doa-doa harian seperti } \\
\text { doa sebelum makan } \\
\text { 4. Akhlak, dengan materi } \\
\text { keteladanan terhadap } \\
\text { Nabi Muhammad SAW } \\
\text { dan Nabi Musa a.s. }\end{array}$ & $\begin{array}{l}\text { 1. Akidah, menjelaskan dan } \\
\text { memberikan contoh rukun } \\
\text { islam } \\
\text { 2. Akhlak, menyebutkan dan } \\
\text { menjelaskan contoh-contoh } \\
\text { akhlak misalnya rendah hati }\end{array}$ \\
\hline 2. & Metode & $\begin{array}{l}\text { 1. Ceramah } \\
\text { 2. Bercerita dan kisah- } \\
\text { kisah (keteladanan) } \\
\text { 3. Tanya jawab } \\
\text { 4. Latihan } \\
\text { 5. Demonstrasi }\end{array}$ & $\begin{array}{l}\text { 1. Ceramah } \\
\text { 2. Bercerita } \\
\text { 3. Tanya jawab } \\
\text { 4. Latihan } \\
\text { 5. Demonstrasi }\end{array}$ \\
\hline 3. & Media & $\begin{array}{l}\text { 1. Media visual (papan } \\
\text { tulis/white board, } \\
\text { gambar, dan proyektor), } \\
\text { 2. Media audio (rekaman } \\
\text { surat-surat dalam Al- } \\
\text { Qur'an beserta artinya), } \\
\text { 3. Media audio visual }\end{array}$ & $\begin{array}{l}\text { 1. Media visual (white board dan } \\
\text { gambar) } \\
\text { 2. Media audio (rekaman ayat } \\
\text { Al-Qur'an beserta artinya } \\
\text { yang diputar melalui tape } \\
\text { recorder atau laptop). }\end{array}$ \\
\hline
\end{tabular}




\begin{tabular}{|c|c|c|c|}
\hline & & $\begin{array}{lr}\text { (laptop } & \text { dengan } \\
\text { menayangkan } & \text { film-film } \\
\text { mengenai } & \text { kehidupan } \\
\text { Nabi SAW dan } & \text { Nabi } \\
\text { Musa a.s } & \text { saat } \\
\text { berdakwah). } & \end{array}$ & \\
\hline 4. & Evaluasi & $\begin{array}{l}\text { 1. Tes lisan } \\
\text { 2. Tes tulis }\end{array}$ & $\begin{array}{l}\text { 1. Tes lisan } \\
\text { 2. Tes tertulis } \\
\text { 3. Praktik }\end{array}$ \\
\hline 5. & Kendala & $\begin{array}{l}\text { 1. Belum tersedianya buku } \\
\text { bagi siswa dan buku } \\
\text { untuk guru yang sesuai } \\
\text { dengan kurikulum } \\
\text { 2. Ksulitan dalam } \\
\text { penyampaian materi- } \\
\text { materi yang harus sesuai } \\
\text { dengan kurikulum } 2013 \\
\text { 3. Pemahaman guru yang } \\
\text { masih berbeda-beda } \\
\text { mengenai kurikulum } \\
\text { 2013 } \\
\text { 4. Sistem penilaian dari } \\
\text { pencapaian kurikulum } \\
\text { 2013 } \\
\text { Keterbatasan jumlah } \\
\text { guru }\end{array}$ & $\begin{array}{l}\text { 1. Kurangnya fasilitas yang } \\
\text { memadai } \\
\text { 2. Belum adanya buku guru yan } \\
\text { dibuat oleh pihak terkait } \\
\text { 3. Sistem pendidikan masa lalu } \\
\text { yang masih diterapkan sampai } \\
\text { saat ini }\end{array}$ \\
\hline 6. & $\begin{array}{c}\text { Strategi } \\
\text { Mengatasi Hambatan }\end{array}$ & $\begin{array}{l}\text { 1. Sumber daya manusia } \\
\text { yaitu guru PAI yang } \\
\text { telah mengikuti diklat } \\
\text { K13 dan membuat buku }\end{array}$ & $\begin{array}{l}\text { 1. Mendorong guru untuk lebih } \\
\text { kreatif, misalnya menyusun } \\
\text { sendiri bahan ajar untuk } \\
\text { digunakan di internal sekolah }\end{array}$ \\
\hline
\end{tabular}




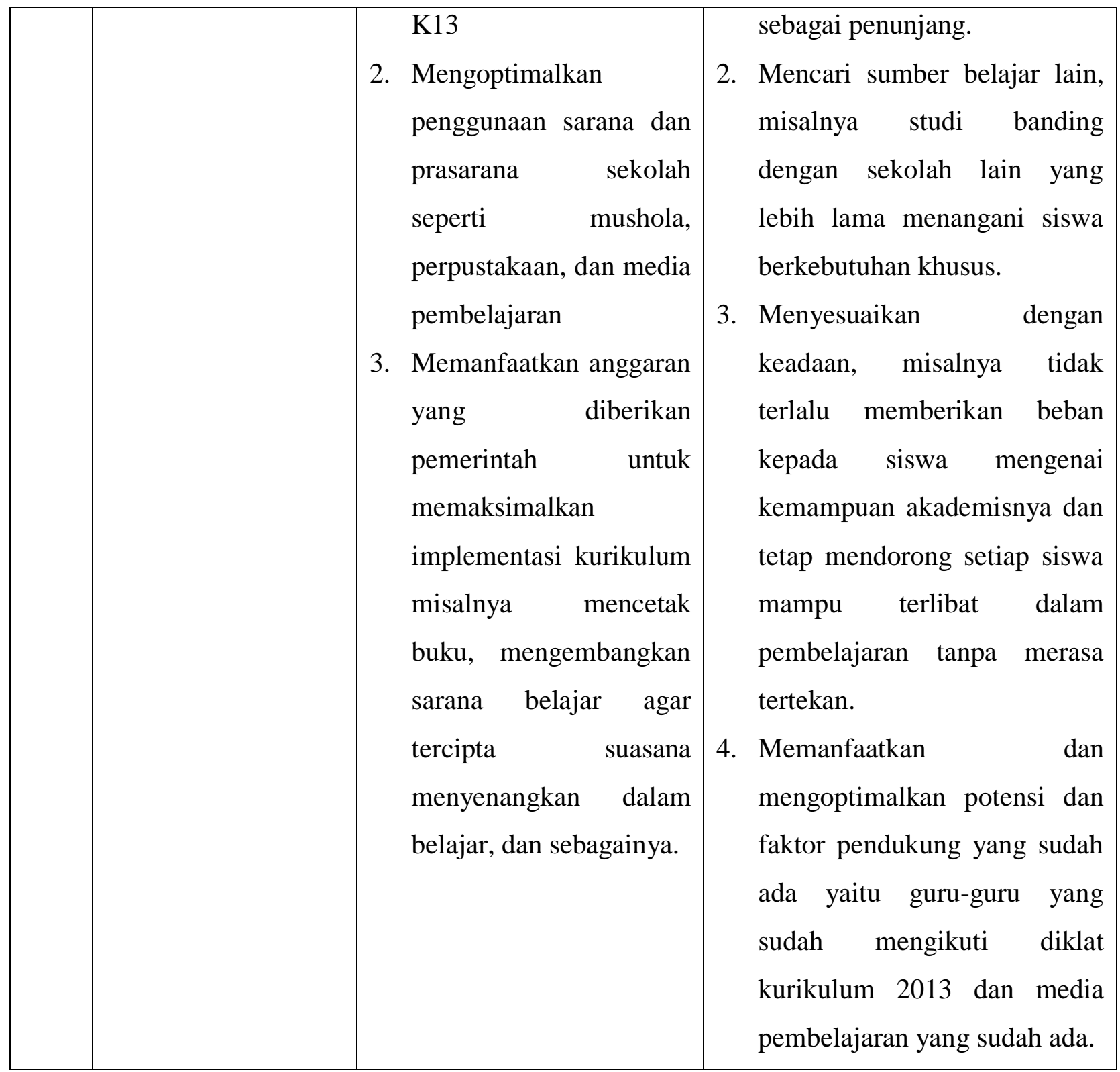

\section{KESIMPULAN}

1. Pembelajaran PAI dalam menerapkan scientific learning dalam menguatkan keagamaan siswa tunagrahita jenjang SDLB di SLB Negeri Pembina Yogyakarta meliputi materi, metode, dan media pembelajaran. Materi yang disampaikan memiliki cakupan lebih luas yaitu meliputi akidah (melalui rukun iman), implementasi akidah misalnya melalui sholat dhuha berjamaah, hafalan surat dalam Al-Qur'an dan doa-doa harian seperti doa sebelum makan, serta keteladanan terhadap Nabi Muhammad SAW dan Nabi Musa a.s. Adapun metode yang digunakan yaitu metode ceramah, bercerita dan kisah-kisah, tanya jawab, latihan, 
dan demonstrasi. Sedangkan media pembelajaran yang digunakan yaitu media visual (papan tulis/white board, gambar, dan proyektor), media audio (rekaman surat-surat dalam Al-Qur'an beserta artinya), serta audio visual (laptop dengan menayangkan film-film mengenai kehidupan Nabi SAW dan Nabi Musa a.s saat berdakwah).

2. Pembelajaran PAI dalam menerapkan scientific learning dalam menguatkan keagamaan siswa tunagrahita jenjang SDLB di SLB Muhammadiyah Gamping juga meliputi materi, metode, dan media pembelajaran. Materi yang disampaikan masih sebatas akidah melalui rukun Islam dan akhlak yang merupaka implementasi dari nilai-nilai spiritual. Materi diberikan secara teori dan diikuti dengan praktik. Adapun metode yang digunakan yaitu ceramah, bercerita, tanya jawab, latihan, dan demonstrasi, sedangkan media yang digunakan yaitu visual (white board dan gambar) dan audio (rekaman ayat Al-Qur'an beserta artinya yang diputar melalui tape recorder atau laptop).

3. Kegiatan keagamaan siswa tunagrahita jenjang SDLB di SLB Negeri Pembina Yogyakarta berhasil meningkat. Hal tersebut berdasarkan evalusi kemampuan siswa menggunakan 2 tolok ukur yaitu tes lisan dan tes tertulis.

4. Kegiatan keagamaan siswa tunagrahita jenjang SDLB di SLB berhasil meningkat. Hal tersebut berdasarkan evalusi kemampuan siswa menggunakan 3 tolok ukur yaitu tes lisan, tes tertulis, dan praktik.

5. Strategi dalam mengatasi kendala yang dihadapi masing-masing SLB sedikit berbeda meskipun kendala hampir sama. Hal ini karena kedua sekolah tersebut memiliki faktor pendukung yang berbeda. Kendala yang dihadapi masih seputar keterbatasan buku ajar baik untuk guru maupun siswa, kesulitas menerapkan scientific learning karena sulitnya menyampaikan materi sesuai kurikulum, sistem penilaian yang sulit, dan keterbatasan guru pengajar. Strategi yang sama yaitu membuat buku ajar sendiri karena masing-masing guru PAI sekolah tersebut telah menerima diklat 2013, selain itu juga mengoptimalkan sarana pendukung yang dimiliki seperti perpustakaan dan mushola. Strategi yang berbeda adalah penggunaan anggaran. SLB Pembina merupakan sekolah negeri yang sudah lama berdiri dan terakreditasi sehingga mendapatkan alokasi dana pengembangan dari pemerintah, sedangkan SLB Muhammadiyah Gamping merupakan yayasan di 
bawah naungan Muhammadiyah yang masih dalam tahap pengembangan karena belum lama berdiri sehingga belum terakreditasi dan mendapatkan dana anggaran seperti SLB Pembina Yogyakarta.

\section{DAFTAR PUSTAKA}

Ahmadi, A. dan Uhbiyatti, N. 2001. Ilmu Pendidikan Islam. Jakarta: PT. Rineka Cipta.

Arief, A. 2002. Pengantar Ilmu dan Metodologi Pendidikan Islam. Jakarta: Ciputat Press.

Arifin. 1996. Ilmu Pendidikan Islam. Jakarta: Bumi Aksara.

Arikunto, S. 2010. Prosedur Penelitian: Suatu Pendekatan Praktek. Jakarta: Rineka Cipta.

Arsyad, A. 2007. Media Pembelajaran. Jakarta : Raja Grafindo Persada.

Asnawir dan M. Basyiruddin Usman. 2002. Media Pembelajaran. Jakarta: Ciputat Pers Asrul, Rusydi Ananda, dan Rosnita. 2015. Evaluasi Pembelajaran. Bandung: Citapustaka Media.

Djamarah, S.B., dan Aswan Zain. 2013. Strategi Belajar Mengajar. Jakarta: Rineka Cipta.

Daradjat, Z. 2001. Metodologi Pengajaran Agama Islam. Jakarta: Bumi Aksara.

Daryanto. 2014. Pendekatan Pembelajaran Saintifik Kurikulum 2013. Yogyakarta: Gava Media.

Departemen Agama RI Direktorat Jenderal Kelembagaan Agama Islam. Memahami Paradigma Baru Pendidikan Nasional dalam Undang-Undang Sisdiknas. Jakarta: Ditjen Kelembagaan Agama Islam Depag, 2003.

Direktorat Pendidikan Luar Biasa. 2008. Informasi Pelayanan Pendidikan Bagi Anak Tunagrahita. http://www.ditplb.or.id/profile.php?id=45. Diunduh tanggal 25 Januri 2013.

Efendi, M. 2006. Pengantar Psikopedagogik Anak Berkelainan. Jakarta: Bumi Aksara.

Hamalik, O. 1993. Pengembangan Kurikulum Lembaga Pendidikan dan Pelatihan. Bandung: PT. Trigenda Karya.

Haryati, M. 2008. Model dan Teknik Penilaian pada Tingkat Satuan Pendidikan, (Jakarta: Gaung Persada Press. 
Marzuenda. 2013. Pelaksanaan Pembelajaran Pendidikan Agama Islam di Sekolah Luar Biasa Sri Mujinab Pekanbaru. Tesis. Universitas Islam Negeri Sultan Syarif Kasim Pekanbaru.

Musfiqon. 2012. Pengembangan Media dan Sumber Pembelajaran. Jakarta: PT Prestasi Pustakaraya.

Nata, A. 1997. Filsafat Pendidikan Islam. Jakarta: Logos Wacana Ilmu.

Nazarudin. 2007. Manajemen Pembelajaran: Implementasi Konsep, Karakteristik, dan Metodologi Pendidikan Agama Islam di Sekolah Umum. Yogyakarta: Teras.

Ramayulis.1990. Metodologi Pengajaran Agama Islam. Jakarta: Kalam Mulia.

Shihab, Q. 1996. Membumikan Al-Qur'an. Bandung: Mizan.

Somantri, S. 2006. Psikologi Anak Luar Biasa. Bandung : Rafika Aditama.

Sugiyono. 2011. Metode Penelitian Pendidikan (Pendekatan Kuantitatif, Kualitatif dan $R \& D)$. Bandung: Alfabeta.

Sukardi. 2008. Metodologi Penelitian Pendidikan. Yogyakarta: Bumi Aksara.

Sukmadinata. 2007. Metode Penelitian Pendidikan. Bandung: PT Remaja Rosdakarya

Syah, M. 2008. Psikologi Pendidikan dengan Pendekatan Baru. Bandung: PT Remaja Rosdakarya.

Uhbiyati, N. dan Abu Ahmadi. 1997. Ilmu Pendidikan Islam I. Bandung: Pustaka Setia.

Undang-undang Republik Indonesia. No.22 Tahun 2003 tentang SISDIKNAS. Bandung: Citra Umbara, 2006.

Usman, B. 2005. Metodologi Pembelajaran Agama Islam. Jakarta: Ciputat Press.

Zulkifli. 2003. Psikologi Perkembangan. Bandung: PT Remaja Rosdakarya 